\title{
Speed sensorless vector control of parallel-connected three-phase two-motor single-inverter drive system
}

\author{
R. Gunabalan ${ }^{\mathrm{a}}$, P. Sanjeevikumar ${ }^{\mathrm{b} \star}$, Frede Blaabjerg ${ }^{\mathrm{c}}$, Patrick W. Wheeler ${ }^{\mathrm{d}}$, Olorunfemi Ojo ${ }^{\mathrm{e}, \mathrm{f}}$, and \\ Ahmet H. Ertas ${ }^{g}$ \\ ${ }^{a}$ School of Electrical and Electronics Engineering, Vellore Institute of Technology University, \\ Chennai 600 127, India, ${ }^{\mathrm{b}}$ Research and Development, Ohm Technologies, Chennai 600 122, India, \\ 'Department of Energy Technology, Center for Reliable Power Electronics (CORPE), Aalborg University, \\ Pontoppidanstraede 101, 9220 Aalborg, Denmark, ${ }^{\mathrm{d} D e p a r t m e n t ~ o f ~ E l e c t r i c a l ~ a n d ~ E l e c t r o n i c s ~ E n g i n e e r i n g, ~}$ \\ Institute of Aerospace Technology, and Power Electronics, Machines and Control Group (PEMC), \\ Nottingham University, Nottingham NG7 2RD, United Kingdom, ${ }^{\mathrm{e} D e p a r t m e n t}$ of Electrical and \\ Computer Engineering, Center for Energy System Research, Tennessee Technological University, \\ Cookeville, TN 38505, USA, ${ }^{f}$ Eskom Centre of Excellence in HVDC Engineering, University of \\ KwaZulu-Natal, Durban 4041, South Africa, ${ }^{\mathrm{g} D e p a r t m e n t}$ of Biomedical Engineering, Karabuk \\ University, Demir-Celik Campus, Baliklarkayasi Mevkii, 78050 Karabuk, Turkey \\ *sanjeevi12@yahoo.co.in
}

\section{Abstract}

This paper presents the characteristic behavior of direct vector control of two induction motors with sensorless speed feedback having the same rating parameters, paralleled combination, and supplied from a single current-controlled pulse-width-modulated voltage-source inverter drive. Natural observer design technique is known for its simple construction, which estimates the speed and rotor fluxes. Load torque is estimated by load torque adaptation and the average rotor flux was maintained constant by rotor flux feedback control. The technique's convergence rate is very fast and is robust to noise and parameter uncertainty. The gain matrix is absent in the natural observer. The rotor speed is estimated from the load torque, stator current, and rotor flux. Under symmetrical load conditions, the difference in speed between two induction motors is reduced by considering the motor parameters as average and difference. Rotor flux is maintained constant by the rotor flux control scheme with feedback, and the estimation of rotor angle is carried out by the direct vector control technique. Both balanced and unbalanced load conditions are investigated for the proposed AC motor drive system. Experimental results presented in this paper show good agreement with the theoretical formulations.

Key words: estimator, field oriented control, induction motor, natural observer, sensorless vector control, speed control

\section{Introduction}

Controlling of AC motor drives in closed-loop strategy requires the speed transducers, such as tacho generators, resolvers, or digital encoders, to obtain the speed information that leads to the expensive system. In speed sensorless vector control, the speed can be estimated based on the information of line voltages and currents, and its accuracy is mostly meant for a single-inverter-driven single induction motor. In the case of practical needs such as electric traction and steel processing sectors, two or three 
similar rated induction motors are required with parallel operation fully controlled by a single-stage inverter drive (Bose 2001; Guzinski et al. 2009; 2010). If the machines have the same speed-torque characteristics, then speeds are equal, and torque-sharing rates are equal in all operating conditions. Practically, there will be observable differences between behaviors of machines. The speeds may not be identical because of slight difference of wheel diameters. The speed-torque characteristics that cause the different torque sharing at the same speed for slightly far from being identical machines are shown in Fig. 1 (dark blue-motor 2, green line-motor 1). If the wheel diameter of machine 1 is a bit larger than that of machine 2 , then the torque sharing of machine 1 will be higher in motoring mode, but lower in braking mode, the corresponding characteristic of which is represented in Fig. 1 (blue line). In practice, both dissimilar machine characteristics and unequal wheel diameter problems exist. In these circumstances, the speed-torque behavior of both motors differs and an unbalanced condition arises (red line-motor 1, pink line-motor 2). If average currents flow through the stator windings and rotor fluxes are considered to be induced under unbalanced load conditions, then the speeds of both motors deviate much from the command speed. To reduce this speed variations, average and differential currents are used to determine the reference current.

Four induction motors controlled by a single-stage inverter drive as described by Taniguchi et al. (2006) and Kono et al. (2000), and proportional-integral (P-I) current controllers were used to generate $d-q$ axes reference voltage signals. Simulation results of a four-motor drive system and the general equation for $n$ number of motors connected in parallel were described by Kono et al. (2000). Additional proportional speed controllers were implemented with existing $P-I$ controllers to improve the performance under unbalanced load conditions. In the case of multimotor drive systems, the currents flowing both average and difference through the stator as well as rotor fluxes were considered to improve the performance under unbalanced load conditions (Nishimura et al. 2007; Kawai et al. 2002; Inoue et al. 2011a, 2011b; Ruxi et al. 2006; Wei et al. 2006; Ando et al. 2004; Kouno et al. 2001; Matsuse et al. 2002; Kazuya et al. 2012; Yoshinaga et al. 2008). Most of the research papers dealt only with the hardware results for step change in speed under zero load conditions. A low-cost matrix converter with slip-frequency vector control is discussed by Yoshinaga et al. (2008), Osawa (2011a, 2011b), and Yamazaki et al. (2012). To minimize the speed difference among the induction motors under unbalanced load conditions, two-degree-of-freedom control was applied. Two more $P$ controllers were introduced to improve the performance in addition to the $P-I$ controllers presented in both speed control loops. In all the above literature, the estimation of speed and rotor fluxes were employed by the adaptive observers. The selection of gain matrix constant $k$ is a tedious task by adaptive observers where the typical value of $k$ is taken as 0.5 . A new hybrid control method (speed-torque controller) projected on equalized load with power sharing between two drives for cement kiln operation is discussed by Bogiatzidis et al. (2012), Karanayil et al. (2007), and Wlas et al. (2008).

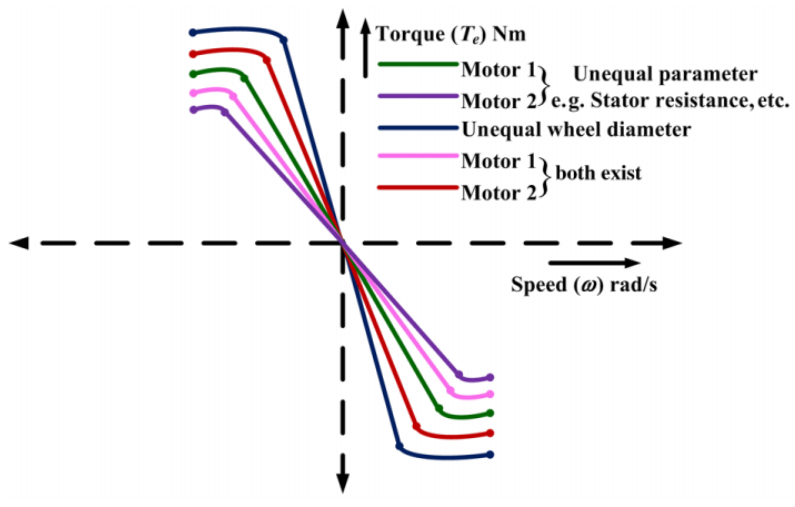

Fig. 1. Speed-torque characteristics of parallel-connected induction motor drives. 
Parallel-connected induction motors fed by a single-stage inverter were reviewed in Trentin et al. (2009) in light of merits and demerits of each method.

The performance of the induction motor drive is affected by motor parameters particularly at low-speed operation. In particular, the indirect field oriented vector control drive is very sensitive to rotor resistance. However, the stator resistance effect is significant in low-speed operation and by knowing its good precision value, the accurate estimation of rotor speed can be obtained. The variation of rotor resistance found to be $100 \%$ at the maximum due to rotor heating as reported by Rashed et al. (2003), Barut et al. (2007, 2008), and Bowes et al. (2004). In particular, small deviations in stator resistance, rotor resistance, and (transient and magnetizing) inductance value cause oscillations in estimated speed. Furthermore, performance deterioration can be ensured by neglecting iron loss of the induction motor model, which in turn causes errors in rotor flux, slip, and torque calculations. Neural networks, genetic algorithm, model reference adaptive system, and extended Kalman filter are used to estimate the unknown parameters accurately (Rashed et al. 2003; Barut et al. 2007, 2008; Bowes et al. 2004).

To overcome the difficulties stated above, natural observer is used to calculate the estimation of the speed, stator current, and rotor fluxes of both motors, as carried out in this paper. The direct field oriented vector control scheme is employed to calculate the flux angle. Average rotor flux derived from both induction motors is kept constant by rotor flux feedback control (Gunabalan et al. 2015, in press). Average and differential currents flowing through the stator and rotor fluxes are used to calculate the reference current. Experimental results are presented for balanced and unbalanced load environmental circumstances to prove the effectiveness of the method, as proposed.

The paper is organized as follows: "Analysis of speed estimation using observer" section discusses the concepts of natural observer, "Parallel connected two induction motor drive" section explains about necessary equations, "Experimental implementation and results" section presents the experimental results under various running conditions, and finally ends with "Conclusions" section.

\section{Analysis of speed estimation using observer}

The structure of the natural observer is similar to and as well as its characteristic is identical to the induction motor for the given input voltage and load torque condition. It should be noted that the convergence rate of the observer is faster than that of the motor in reaching the steady-state behavior. For estimating the rotor speed by natural observer, the fourth-order induction motor model in stator flux oriented reference frame is used, where stator currents and rotor fluxes are considered as state variable parameters.

Therefore, a three-phase induction motor can be represented in state space as follows:

$$
\begin{gathered}
\frac{\mathrm{d} X}{\mathrm{~d} t}=A x+B u \\
Y=C x
\end{gathered}
$$

where

$$
A=\left[\begin{array}{cccc}
\frac{-1}{T_{S}} & 0 & \frac{L_{m}}{L_{s}^{\prime} \tau_{r} \tau_{r}} & \frac{\omega_{r} L_{m}}{L_{L}^{\prime} L_{r}} \\
0 & \frac{-1}{T_{S}} & \frac{-\omega_{r} L_{m}}{L_{L}^{\prime} L_{r}} & \frac{L_{m}}{L_{s}^{\prime} L_{r} \tau_{r}} \\
\frac{L_{m}}{\tau_{r}} & 0 & \frac{-1}{\tau_{r}} & -\omega_{r} \\
0 & \frac{L_{m}}{\tau_{r}} & \omega_{r} & \frac{-1}{\tau_{r}}
\end{array}\right] ; B=\left[\begin{array}{cc}
\frac{1}{\sigma L_{S}} & 0 \\
0 & \frac{1}{\sigma L_{S}} \\
0 & 0 \\
0 & 0
\end{array}\right] ; C=\left[\begin{array}{cccc}
1 & 0 & 0 & 0 \\
0 & 1 & 0 & 0
\end{array}\right]
$$


$\frac{1}{T_{s}}=\frac{R_{s}+R_{r}\left(L_{m} / L_{r}\right)^{2}}{L_{s}^{\prime}} ; L_{s}^{\prime}=\sigma L_{s}$.

where

$\sigma=1-\frac{L_{m}^{2}}{L_{s} L_{r}}$, leakage coefficient;

$x=\left[\begin{array}{llll}i_{d s}^{s} & i_{q s}^{s} & \varphi_{d r}^{s} & \varphi_{q r}^{s}\end{array}\right]^{T} ; Y=\left[\begin{array}{cc}i_{d s}^{s} & i_{q s}^{s}\end{array}\right]=i_{s} ; u=\left[\begin{array}{cc}V_{d s}^{s} & V_{q s}^{s}\end{array}\right]^{T} ;$

$R_{s}, R_{r}$ : stator and rotor self-inductance $(\Omega)$, respectively;

$L_{s}, L_{r}$ : stator and rotor self-inductance $(\mathrm{H})$, respectively;

$L_{m}$ : mutual inductance $(\mathrm{H})$;

$\omega_{r}:$ rotor time constant $=L_{r} / R_{r}$;

$\tau_{r}$ : motor angular velocity $(\mathrm{rad} / \mathrm{s})$.

Figure 2 shows the block diagram representation of the natural observer, and the system described by eqs. (1) and (2) is exactly in the same form of the induction motor model without any external feedback. Estimation of the stator currents and the rotor fluxes can be represented by the following equations:

$$
\begin{gathered}
\frac{\mathrm{d} \hat{X}}{\mathrm{~d} t}=A \hat{x}+B u \\
\hat{Y}=C \hat{x}
\end{gathered}
$$

where

$$
\begin{aligned}
& A=\left[\begin{array}{cccc}
\frac{-1}{T_{S}} & 0 & \frac{L_{m}}{L_{s}^{\prime} \tau_{2} \tau_{r}} & \frac{\hat{\omega}_{r} L_{m}}{L_{L}^{\prime} L_{r}} \\
0 & \frac{-1}{T_{s}} & \frac{-\hat{\omega}_{r} L_{m}}{L_{s} L_{r}} & \frac{L_{m}^{\prime}}{L_{s}^{\prime} r_{r} \tau_{r}} \\
\frac{L_{m}}{\tau_{r}} & 0 & \frac{-1}{\tau_{r}} & -\hat{\omega}_{r} \\
0 & \frac{L_{m}}{\tau_{r}} & \hat{\omega}_{r} & \frac{-1}{\tau_{r}}
\end{array}\right] ; B=\left[\begin{array}{cc}
\frac{1}{\sigma L_{S}} & 0 \\
0 & \frac{1}{\sigma L_{S}} \\
0 & 0 \\
0 & 0
\end{array}\right] ; C=\left[\begin{array}{cccc}
1 & 0 & 0 & 0 \\
0 & 1 & 0 & 0
\end{array}\right] \\
& \hat{x}=\left[\begin{array}{llll}
\hat{i}_{d s}^{s} & \hat{i}_{q s}^{s} & \hat{\varphi}_{d r}^{s} & \hat{\varphi}_{q r}^{s}
\end{array}\right]^{T} ; \quad u=\left[\begin{array}{ll}
V_{d s}^{s} & V_{q s}^{s}
\end{array}\right]^{T} ; \quad \hat{Y}=\left[\begin{array}{ll}
\hat{i}_{d s}^{s} & \hat{i}_{q s}^{s}
\end{array}\right]^{T}=\hat{i}_{s}
\end{aligned}
$$

The estimated quantities are denoted by "^".

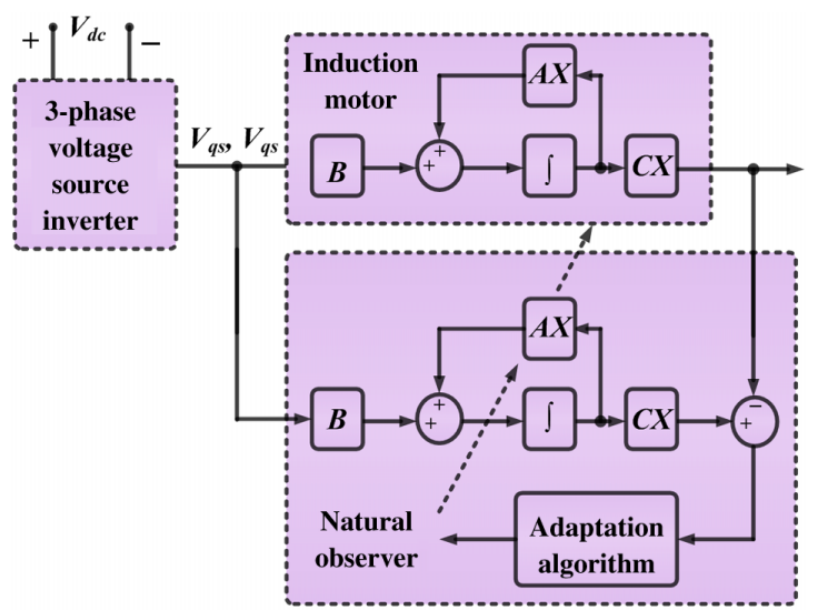

Fig. 2. Block diagram of a natural observer. 
Load torque is estimated by the active power error because the correction term and $\hat{T}_{L}$ load torque are kept within two known limits to avoid unstable oscillations. Estimation of load torque is given by Gunabalan et al. (2015, in press):

$$
\hat{T}_{L}=K_{D} e_{P}+K_{P} e_{P}+K_{I} \int e_{P} \mathrm{~d} t \quad \text { limiting } \hat{T}_{L} \in\left(T_{\min }, T_{\max }\right)
$$

where

$$
e_{P}=V_{d s}^{s}\left(\hat{i}_{d s}^{e}-i_{d s}^{e}\right)+V_{q s}^{s}\left(\hat{i}_{q s}^{e}-i_{q s}^{e}\right)
$$

Estimation of rotor speed can be obtained from the estimated stator current, rotor flux, and load torque as follows:

$$
\dot{\hat{\omega}}_{r}=\left(\frac{3}{2}\right)\left(\frac{n_{p}}{J}\right)\left(\frac{L_{m}}{L_{r}}\right)\left[\hat{\varphi}_{d r}^{s} \hat{i}_{q s}^{s}-\hat{\varphi}_{q r}^{s} \hat{i}_{d s}^{s}\right]-\frac{\hat{T}_{L}}{J}
$$

where $n_{p}$ is the number of pole pairs and $J$ is the inertia of motor load system $\left(\mathrm{kg} \mathrm{m}^{2}\right)$.

\section{Parallel-connected two induction motor drive}

The current flowing in the parallel-connected induction motors supplied from a single-stage inverter drive is shown in Fig. 3 (Yoshinaga et al. 2008). If the current flowing in each motor is unbalanced, and if there is a slight difference between the wheel diameters or the machine parameters, this causes unbalanced load conditions where $i_{s 1}$ will not be equal to $i_{s 2}$. In this situation, the average current and torque can be expressed as follows:

$$
\bar{i}_{s}=\frac{i_{s 1}+i_{s 2}}{2}
$$

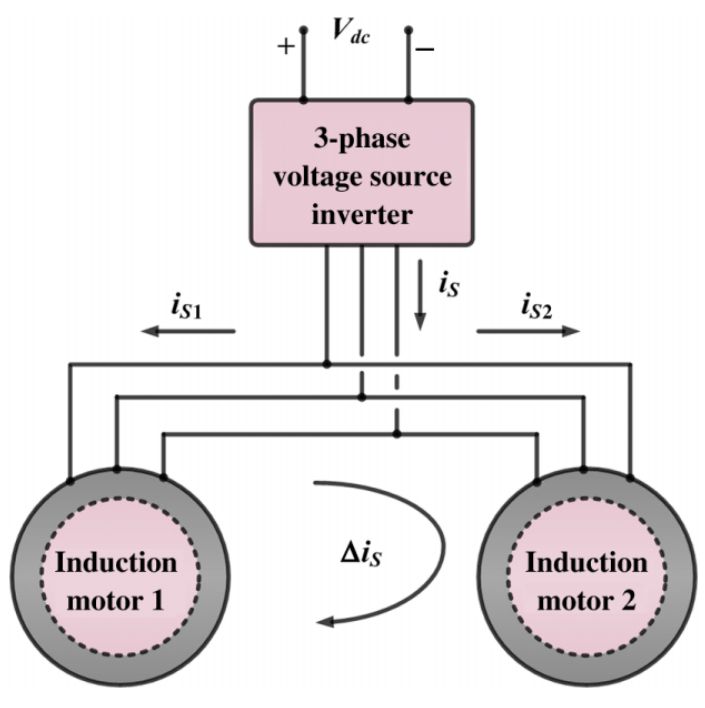

Fig. 3. Configuration of parallel-connected induction motor drives. 


$$
\bar{T}_{e}=\frac{T_{e 1}+T_{e 2}}{2}=T_{e}^{*}
$$

where $T_{1}$ and $T_{2}$ are derived from the speed controllers.

Average current $\bar{i}_{s}$ is compared with the reference current $i_{s}^{*}$ to generate the control voltage for the inverter. Figure 4 shows the configuration of parallel-connected induction motor drive fed by a single-stage inverter drive; main components are natural observer with adaptive load torque estimation, calculation block of reference current values, and current regulated pulse width modulated (CRPWM) voltage-source inverter. With the measured line voltage and currents, the speeds of both motors are estimated and the torque reference of each motor is calculated from the speed error using $P-I$ controllers. Correspondingly, the space vector model of induction motor is used to derive the equations for $i_{d s}$ and $i_{q s}$ as follows:

$$
\begin{gathered}
V_{d s}^{e}=i_{d s}^{e} R_{s}+p \varphi_{d s}^{e}+j \omega_{e} \varphi_{d s}^{e} \\
V_{q s}^{e}=i_{q s}^{e} R_{s}+p \varphi_{q s}^{e}+j \omega_{e} \varphi_{q s}^{e} \\
0=i_{d r}^{e} R_{r}+p \varphi_{d r}^{e}+j\left(\omega_{e}-\omega_{r}\right) \varphi_{d r}^{e} \\
0=i_{q r}^{e} R_{r}+p \varphi_{q r}^{e}+j\left(\omega_{e}-\omega_{r}\right) \varphi_{q r}^{e} \\
\varphi_{d s}^{e}=L_{s} i_{d s}^{e}+L_{m} i_{d r}^{e}
\end{gathered}
$$

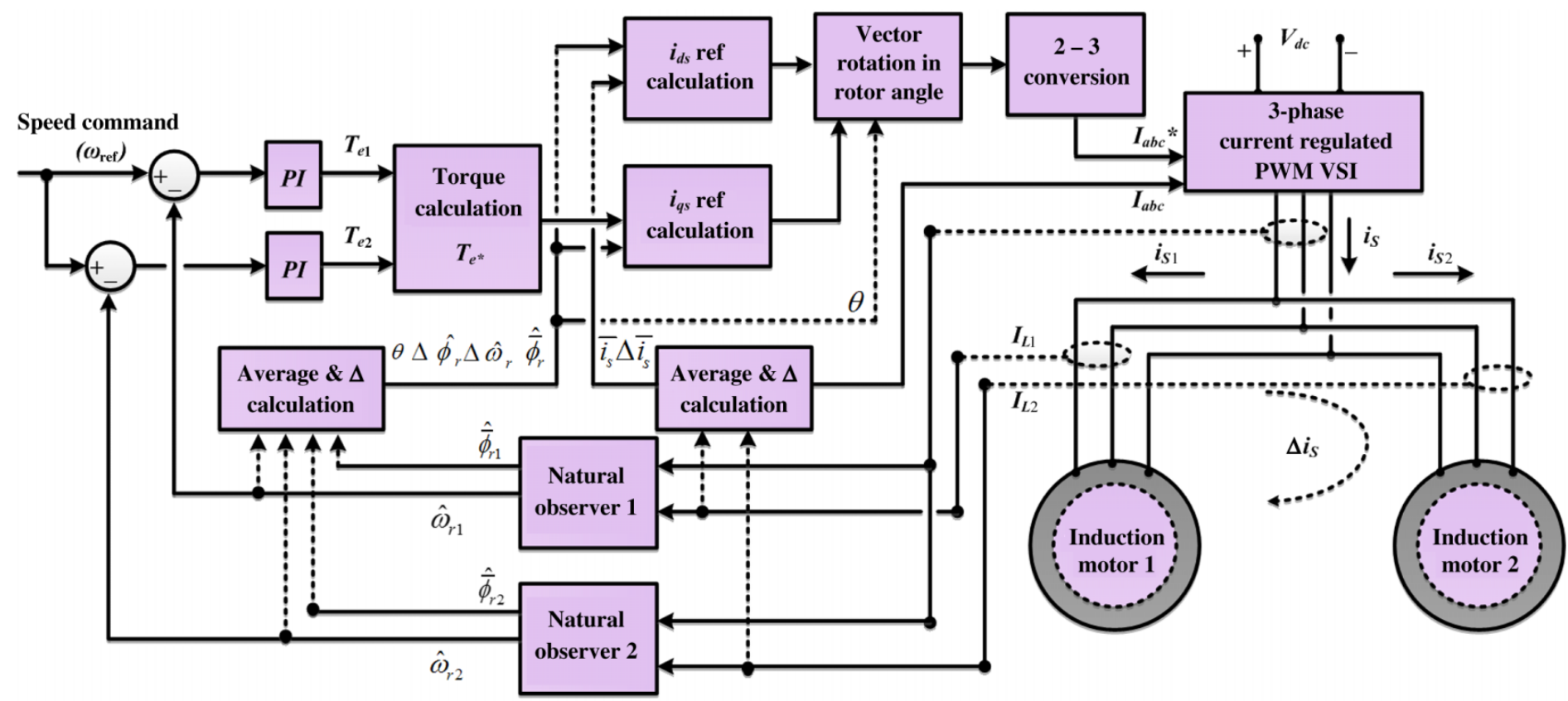

Fig. 4. Configuration of parallel-connected induction motor drives. 


$$
\begin{gathered}
\varphi_{q s}^{e}=L_{s} i_{q s}^{e}+L_{m} i_{q r}^{e} \\
\varphi_{d r}^{e}=L_{r} i_{d r}^{e}+L_{m} i_{d s}^{e} \\
\varphi_{q r}^{e}=L_{r} i_{q r}^{e}+L_{m} i_{q s}^{e} \\
T_{e}=\frac{3}{2} \frac{P}{2}\left(\frac{L_{m}}{L_{r}}\right)\left(\varphi_{d r}^{e} i_{q s}^{e}-\varphi_{q r}^{e} i_{d s}^{e}\right)
\end{gathered}
$$

From eq. (12),

$$
i_{d r}^{e}=\frac{-p \varphi_{d r}^{e}-j\left(\omega_{e}-\omega_{r}\right) \varphi_{d r}^{e}}{R_{r}}
$$

By substituting this expression in eq. (16), we get

$$
\varphi_{d r}^{e}=L_{r} \frac{-p \varphi_{d r}^{e}-j\left(\omega_{e}-\omega_{r}\right) \varphi_{d r}^{e}}{R_{r}}+L_{m} i_{d s}^{e}
$$

Further after simplification,

$$
\begin{aligned}
& p \varphi_{d r}^{e}+\left\{S_{r}+j\left(\omega_{e}-\omega_{r}\right)\right\} \varphi_{d r}^{e}=L_{m} S_{r} i_{d s}^{e} \\
& p \varphi_{q r}^{e}+\left\{S_{r}+j\left(\omega_{e}-\omega_{r}\right)\right\} \varphi_{q r}^{e}=L_{m} S_{r} i_{q s}^{e}
\end{aligned}
$$

From eqs. (21) and (22), the general equation is represented as

$$
p \varphi_{r}^{e}+\left\{S_{r}+j\left(\omega_{e}-\omega_{r}\right)\right\} \varphi_{r}^{e}=U i_{s}^{e}
$$

where

$$
U=S_{r} L_{m} ; S_{r}=\frac{R_{r}}{L_{r}}
$$

The equations for motors 1 and 2, which is connected in parallel, are

$$
\begin{aligned}
& p \varphi_{r 1}^{e}+\left\{S_{r 1}+j\left(\omega_{e}-\omega_{r 1}\right)\right\} \varphi_{r 1}^{e}=U_{1} i_{s 1}^{e} \\
& p \varphi_{r 2}^{e}+\left\{S_{r 2}+j\left(\omega_{e}-\omega_{r 2}\right)\right\} \varphi_{r 2}^{e}=U_{2} i_{s 2}^{e}
\end{aligned}
$$

respectively.

By averaging and differential averaging eqs. (24) and (25), we obtain

$$
p \bar{\varphi}_{r}^{e}+\left\{\bar{S}_{r}+\left(\omega_{e}-\bar{\omega}_{r}\right)\right\}+\left\{\Delta \bar{S}_{r}-\Delta \bar{\omega}_{r}\right\} \Delta \bar{\varphi}_{r}^{e}=\bar{U} \bar{i}_{s}^{e}+\Delta \bar{U} \Delta \bar{i}_{s}^{e}
$$

The differential parameters between the two motors are defined as

$\Delta \bar{S}_{r}=\frac{S_{r 2}-S_{r 1}}{2} ; \quad \Delta \bar{\omega}_{r}=\frac{\omega_{r 2}-\omega_{r 1}}{2} ; \quad \Delta \bar{U}=\frac{U_{2}-U_{1}}{2} ; \quad \Delta \bar{i}_{s}^{e}=\frac{i_{s 2}-i_{s 1}}{2} ; \quad \Delta \bar{\varphi}_{r}^{e}=\frac{\varphi_{r 2}-\varphi_{r 1}}{2}$

The above equation can also be written as

$$
p \bar{\varphi}_{r}^{e}+\left\{\bar{S}_{r}+j\left(\omega_{e}-\bar{\omega}_{r}\right)\right\}+\left\{\Delta \bar{S}_{r}-j \Delta \bar{\omega}_{r}\right\} \Delta \bar{\varphi}_{r}^{e}=\bar{U} \bar{i}_{s}^{e}+\Delta \bar{U} \Delta \bar{i}_{s}^{e}
$$

and by separating the real from imaginary part, 


$$
p \bar{\varphi}_{d r}^{e}+\bar{S}_{r} \varphi_{d r}^{e}-\left(\omega_{e}-\bar{\omega}_{r}\right) \bar{\varphi}_{q r}^{e}+\Delta \bar{S}_{r} \Delta \bar{\varphi}_{d r}^{e}+\Delta \bar{\omega}_{r} \Delta \bar{\varphi}_{q r}^{e}=\bar{U} \bar{i}_{d s}^{e}+\Delta \bar{U} \Delta \bar{i}_{d s}^{e}
$$

For constant flux, $p \bar{\varphi}_{d r}^{e}=0 \bar{\varphi}_{q r}^{e}=0 \bar{i}_{q s}^{e}=0$.

After simplification, we have

$$
\bar{i}_{d s}^{e *}=\frac{\bar{S}_{r} \bar{\varphi}_{d r}^{e}+\Delta \bar{\omega}_{r} \Delta \bar{\varphi}_{q r}^{e}+\Delta \bar{S}_{r} \Delta \bar{\varphi}_{d r}^{e}-\Delta \bar{U} \Delta \bar{i}_{d s}^{e}}{\bar{U}}
$$

When the stator current, rotor flux, and speed are estimated using the observer, eq. (29) is represented as

$$
\bar{i}_{d s}^{e *}=\frac{\bar{S}_{r} \bar{\varphi}_{d r}^{e *}+\Delta \overline{\hat{\omega}}_{r} \Delta \overline{\hat{\varphi}}_{q r}^{e}+\Delta \bar{S}_{r} \Delta \overline{\hat{\varphi}}_{d r}^{e}-\Delta \bar{U} \Delta \overline{\hat{i}}_{d s}^{e}}{\bar{U}}
$$

Torque equations for motors 1 and 2 are as follows:

$$
\begin{aligned}
& T_{e 1}=\frac{p L_{m 1}}{L_{r 1}}\left(i_{s 1}^{e} \times \varphi_{r 1}^{e}\right) \\
& T_{e 2}=\frac{p L_{m 2}}{L_{r 2}}\left(i_{s 2}^{e} \times \varphi_{r 2}^{e}\right)
\end{aligned}
$$

By averaging and differential averaging eqs. (31) and (32),

$$
\begin{gathered}
\bar{T}^{*}=p \bar{M}^{\prime}\left(\bar{i}_{s}^{e} \times \bar{\varphi}_{r}^{e}+\Delta \bar{i}_{s}^{e} \times \Delta \bar{\varphi}_{r}^{e}\right) \\
\bar{T}^{*}=p \bar{M}^{\prime}\left(\bar{i}_{d s}^{e} \bar{\varphi}_{q r}^{e}-\bar{i}_{q s}^{e} \bar{\varphi}_{d r}^{e}+\Delta \bar{i}_{d s}^{e} \Delta \bar{\varphi}_{q r}^{e}-\Delta \bar{i}_{q s}^{e} \Delta \bar{\varphi}_{d r}^{e}\right)
\end{gathered}
$$

$\bar{i}_{q s}^{e}$ controls the average torque and $\bar{i}_{d s}^{e}$ is zero.

$$
\begin{gathered}
\frac{\bar{T}^{*}}{p \bar{M}^{\prime}}=\bar{i}_{q s}^{e} \bar{\varphi}_{d r}^{e}+\Delta \bar{i}_{d s}^{e} \times \Delta \bar{\varphi}_{q r}^{e}-\Delta \bar{i}_{q s}^{e} \times \Delta \bar{\varphi}_{d r}^{e} \\
\bar{i}_{q s}^{e *}=\frac{\frac{\bar{T}^{*}}{p \bar{M}^{\prime}}-\Delta \bar{i}_{q s}^{e} \times \Delta \bar{\varphi}_{d r}^{e}+\Delta \bar{i}_{d s}^{e} \times \Delta \bar{\varphi}_{q r}^{e}}{\bar{\varphi}_{d r}^{e *}}
\end{gathered}
$$

When the stator current and the rotor flux are estimated using the observer, eq. (36) is represented as

$$
\begin{gathered}
\bar{i}_{q s}^{e *}=\frac{\frac{\bar{T}^{*}}{p \bar{M}^{\prime}}-\Delta \overline{\hat{i}}_{d s}^{e} \times \Delta \overline{\hat{\varphi}}_{d r}^{e}+\Delta \overline{\hat{i}}_{q s}^{e} \times \Delta \overline{\hat{\varphi}}_{q r}^{e}}{\overline{\hat{\varphi}}_{d r}^{e *}} \\
\bar{T}^{*}=\frac{\bar{T}_{e}-\left(\frac{\Delta \bar{M}^{\prime}}{\bar{M}^{\prime}}\right) \Delta \bar{T}_{e}}{1-\left(\frac{\Delta \bar{M}^{\prime}}{\bar{M}^{\prime}}\right)^{2}}
\end{gathered}
$$

where

$$
\begin{aligned}
& U=S_{r} L_{m} \bar{U}=\frac{U_{1}+U_{2}}{2} \Delta \bar{U}=\frac{U_{2}-U_{1}}{2} \\
& \bar{M}^{\prime}=\frac{1}{2}\left(\frac{L_{m 1}}{L_{r 1}}+\frac{L_{m 2}}{L_{r 2}}\right) \Delta \bar{M}^{\prime}=\frac{1}{2}\left(\frac{L_{m 2}}{L_{r 2}}-\frac{L_{m 1}}{L_{r 1}}\right)
\end{aligned}
$$


$\bar{i}_{s}^{e}=\frac{i_{s 1}^{e}+i_{s 2}^{e}}{2} \Delta \bar{i}_{s}^{e}=\frac{i_{s 2}^{e}-i_{s 1}^{e}}{2}$

$\overline{\hat{\omega}}_{r}=\frac{\hat{\omega}_{r 1}+\hat{\omega}_{r 2}}{2} \Delta \overline{\hat{\omega}}_{r}=\frac{\hat{\omega}_{r 2}-\hat{\omega}_{r 1}}{2}$

$\bar{S}_{r}=\frac{S_{r 1}+S_{r 2}}{2} \Delta \bar{S}_{r}=\frac{S_{r 2}-S_{r 1}}{2}$

$L_{r 1}, L_{r 2}:$ rotor self-inductance of motors 1 and 2 , respectively $(\mathrm{H})$;

$L_{m 1}, L_{m 2}$ : mutual inductance of motors 1 and 2, respectively $(\mathrm{H})$;

$\omega_{r 1}, \omega_{r 2}$ : angular velocity of motors 1 and 2 , respectively $(\mathrm{rad} / \mathrm{s})$.

Table 1. Main parameters of parallel-connected two induction motor drive.

\begin{tabular}{lc}
\hline Rated output power & $745.6 \mathrm{~W}$ \\
Number of poles & 4 \\
Rated speed & $1415 \mathrm{rpm}$ \\
\hline Rated voltage & $415 \mathrm{~V}$ \\
Rated current & $1.8 \mathrm{~A}$ \\
\hline Stator resistance $\left(R_{s}\right)$ & $19.355 \Omega$ \\
Rotor resistance $\left(R_{r}\right)$ & $8.43 \Omega$ \\
\hline Stator inductance $\left(L_{s}\right)$ & $0.715 \mathrm{H}$ \\
\hline Rotor inductance $\left(L_{r}\right)$ & $0.715 \mathrm{H}$ \\
\hline Mutual inductance $\left(L_{m}\right)$ & $0.689 \mathrm{H}$ \\
\hline
\end{tabular}

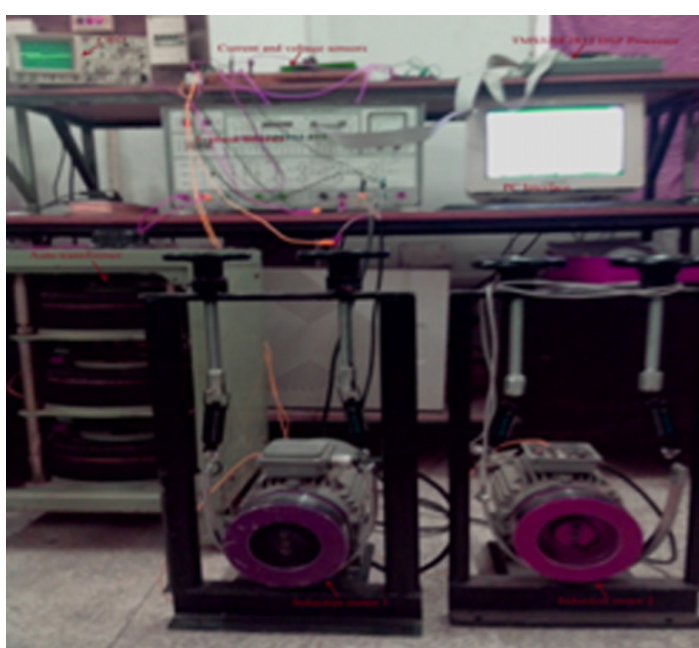

Fig. 5. Experimental set up of parallelconnected induction motor drive controlled by DSP TMS320F2812. 


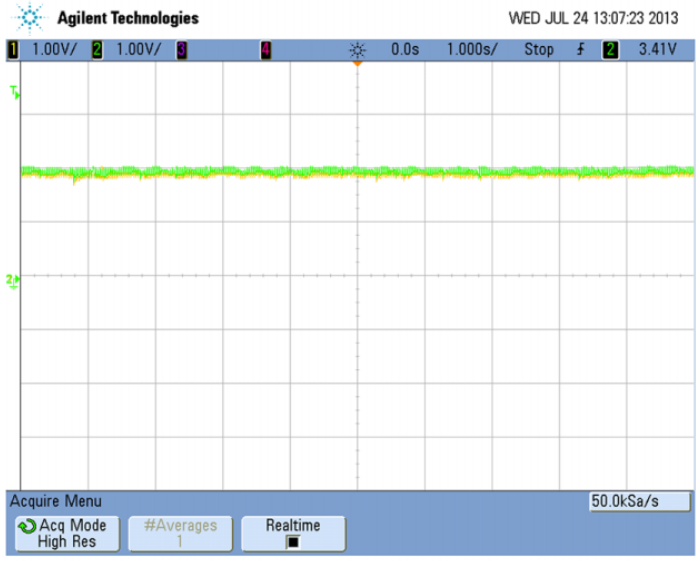

(a)

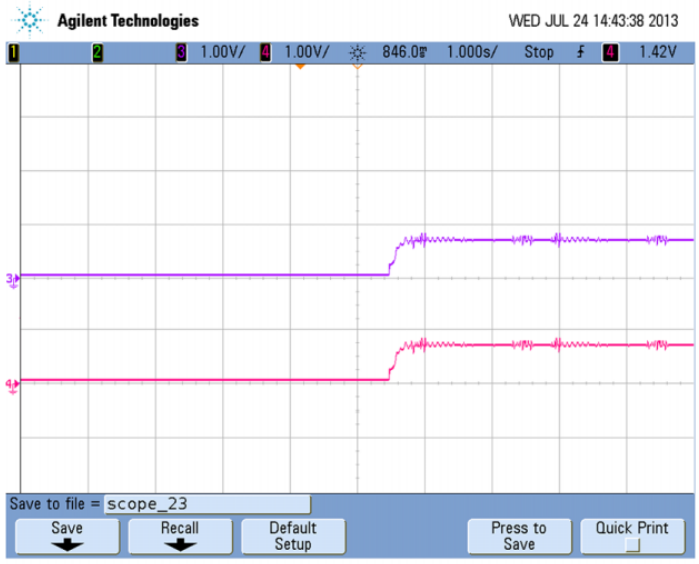

(b)

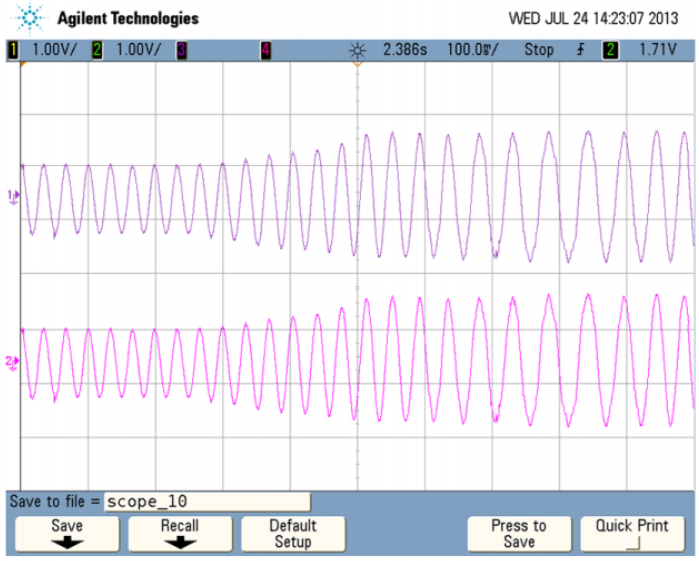

(c)
Fig. 6. Experimental results for balanced load conditions: $(a)$ estimated speed response (green-motor 1, yellow-motor 2), (b) estimated load torque response (pink-motor 1 , purple-motor 2), (c) phase A stator currents (pink-motor 1, purple-motor 2) [500 rpm/ div; $5 \mathrm{Nm} /$ div; $1 \mathrm{~A} / \mathrm{div}$. 


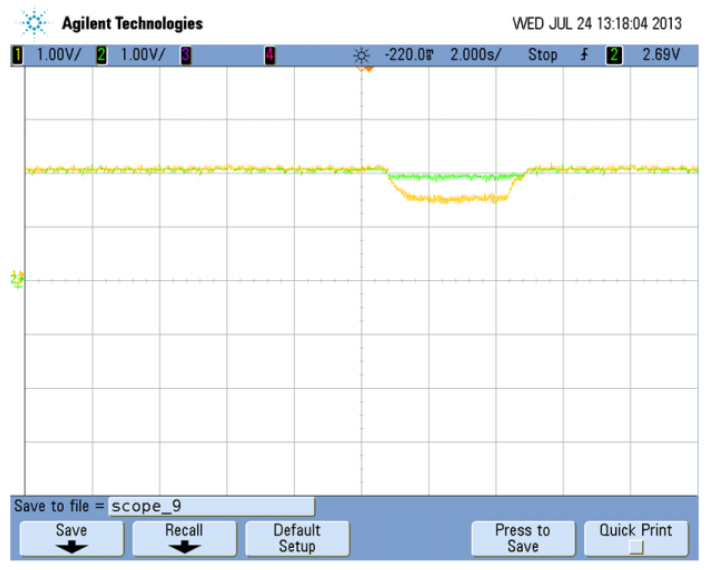

(a)

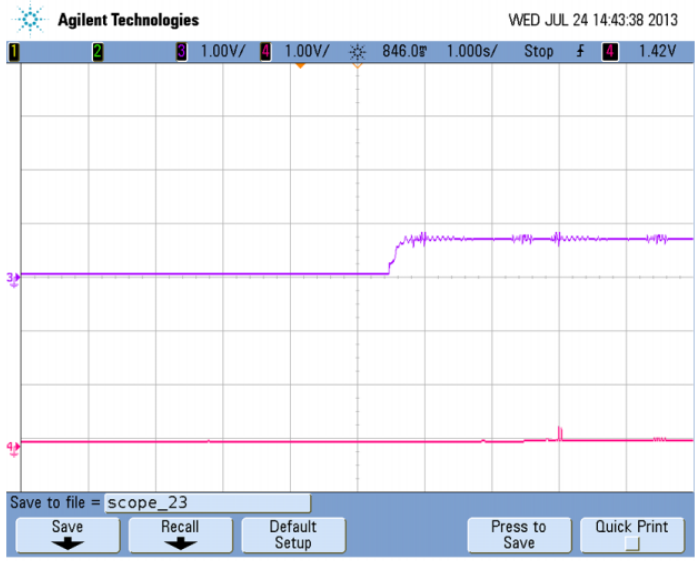

(b)

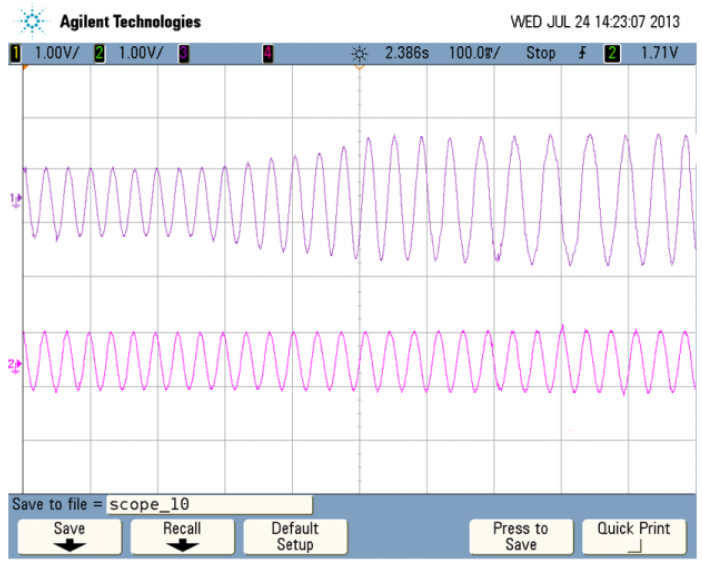

(c)
Fig. 7. Experimental results for unbalanced load conditions when motor 1 loaded: (a) estimated speed response (green-motor 1, yellow-motor 2), (b) estimated load torque response (pink-motor 1, purple-motor 2), (c) phase A stator currents (pink-motor 1, purple-motor 2) $[500 \mathrm{rpm} / \mathrm{div}$; $5 \mathrm{Nm} / \mathrm{div} ; 1 \mathrm{~A} / \mathrm{div}]$. 


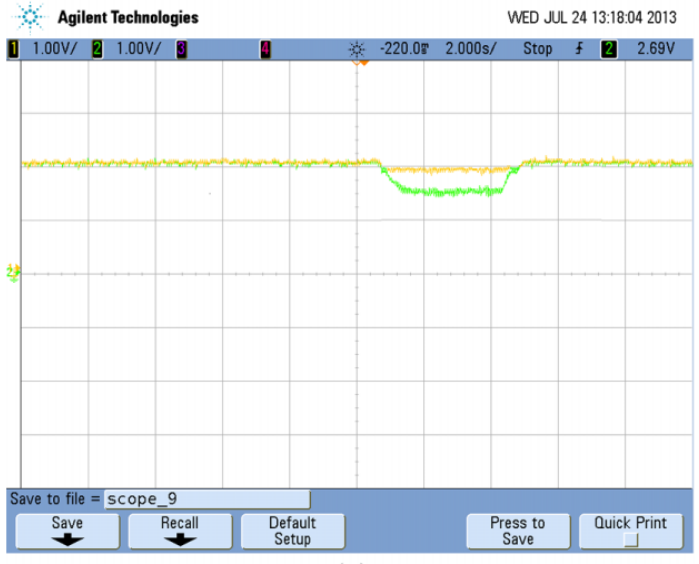

(a)

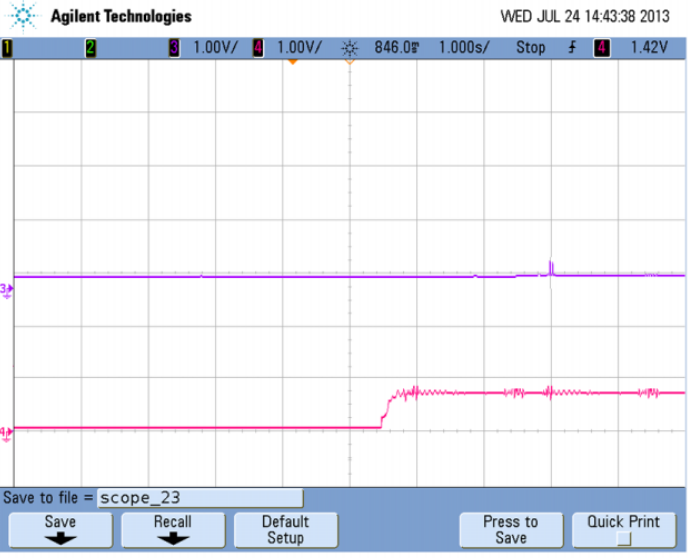

(b)

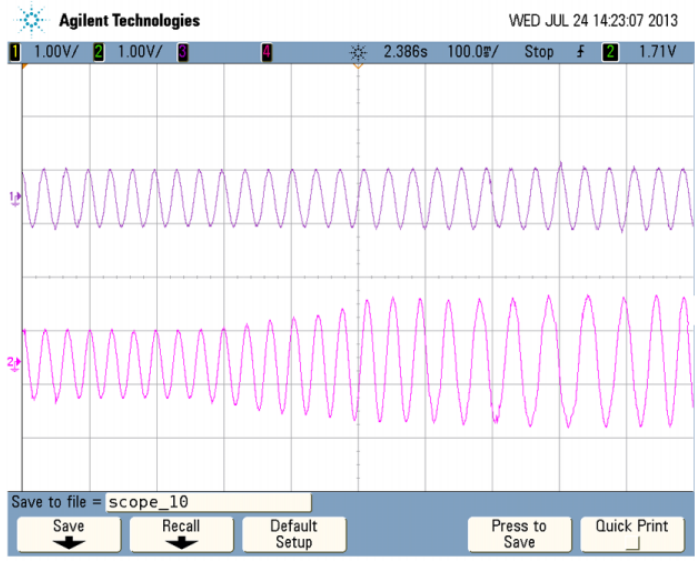

(c)
Fig. 8. Experimental results for unbalanced load conditions when motor 2 loaded: (a) estimated speed response (green-motor 1, yellow-motor 2), (b) estimated load torque response (pink-motor 1, purple-motor 2), (c) phase A stator currents (pink-motor 1, purple-motor 2) $[500 \mathrm{rpm} / \mathrm{div}$; $5 \mathrm{Nm} / \mathrm{div} ; 1 \mathrm{~A} / \mathrm{div}]$. 


\section{Experimental implementation and results}

Two identical three-phase squirrel cage induction motors rated at $745.6 \mathrm{~W}$ (1 HP) are used for parallel-connected configuration (Gunabalan et al. 2015, in press). Table 1 shows the rating and parameters of the induction motor used for experimental task. The direct field oriented sensorless vector control scheme is used and the rotor angle is calculated from the estimated rotor fluxes. The complete experimental prototype set up is shown in Fig. 5. To estimate the speeds and rotor fluxes of induction motors, AD5024 bipolar analog to digital converter with 12-bit resolution measures the currents and voltages. The measured signals are processed in the TMS320F2812 digital signal processor (DSP) to estimate the speed, rotor fluxes, and stator currents.

\section{Balanced load conditions}

Initially, the reference speed is set at $1000 \mathrm{rpm}$ (70\% of rated speed) under no-load conditions and both motors follow the reference speed. After a particular time interval, a load of $4 \mathrm{Nm}(80 \%$ of full-load torque) is applied to both induction motors. Figure $6 a$ illustrates the estimated speed waveform obtained by the experimental set up, which verifies that both motors follow the speed command. The estimated torque waveform is shown in Fig. $6 b$. It follows the actual load torque representing that the system is stable under balanced load conditions. Phase A stator currents of motors 1 and 2 are depicted in Fig. $6 c$, which follows the torque demand and further confirms the balanced condition of the system.

\section{Unbalanced load conditions}

An unbalanced load condition arises, in particular, whenever there is a slight dissimilarity in wheel diameter. To illustrate such conditions in the experimental set up, unequal load is applied to both motors. Both induction motors run at a constant speed of $1000 \mathrm{rpm}$ under no-load conditions initially. Now, motor 2 is loaded with $4 \mathrm{Nm}$ keeping motor 1 at still no-load condition. The estimated speed response obtained under these circumstances is depicted in Fig. 7a. It is indicated that the estimated speed follows the speed set command and deviation occurs when motor 2 is loaded; again it backs to the set value by the PI regulator action. The estimated torque responses of motors 1 and 2 are shown in Fig. $7 b$ and phase A stator currents of motors 1 and 2 are given in Fig. $7 c$. Stator currents confirm the unbalanced running condition, as the phase current of motor 2 is higher than that of motor 1 , when motor 2 is loaded.

Furthermore, the unbalanced condition is verified by setting motor 1 loaded and motor 2 always unloaded. Correspondingly, the estimated speed response is depicted in Fig. $8 a$, torque response of motor 1 and motor 2 is shown in Fig. $7 b$, and phase A stator current of motors 1 and 2 is illustrated in Fig. $7 c$.

\section{Conclusions}

In this paper, the natural observer with load torque adaption technique was presented, in particular to estimate the speed and load torque of motors connected in parallel and fed by a single-stage inverter drive. The structure of the natural observer was simple. An algorithm based on direct vector control in the stationary reference frame was developed, including the natural observer for parameter estimations. The proposed algorithm has been implemented completely using the TMS320F2812 DSP with standard equal rating induction motors. The experimental results for the parallelconnected induction motor drive were demonstrated in literatures only for step change in speed at no load. In this work, experimental results have been provided for multistep change in speed, under balanced load and unbalanced load conditions to prove the effectiveness of the proposed direct vector control with the natural observer adaptation technique. The results shown in this paper always confirm the theoretical hypothesis. 


\section{Author contributions}

Conceived and designed the study: RG, PS. Performed the experiments/collected the data: RG, PS, FB. Analyzed and interpreted the data: RG, PS, OO, AHE. Contributed resources: RG, PS, FB, PWW, OO, AHE. Drafted or revised the manuscript: RG, PS, FB, PWW, OO, AHE.

\section{Data accessibility statement}

All relevant data are within the paper.

\section{References}

Ando I, Sato M, Sazawa M, and Ohishi K. 2004. High efficient parallel connected induction motor speed control with unbalanced load condition using one inverter. In Proceedings of the 29th Annual Conference of the IEEE Industrial Electronics Society, IECON'04, Busan, South Korea, 2-6 November 2004, Vol. 2, pp. 1361-1366. doi:10.1109/IECON.2003.1279973.

Barut M, Bogosyan S, and Gokasan M. 2007. Speed-sensorless estimation for induction motors using extended Kalman filters. IEEE Transaction on Industrial Electronics, 54(1): 272-280. doi:10.1109/TIE .2006.885123.

Barut M, Bogosyan S, and Gokasan M. 2008. Experimental evaluation of braided EKF for sensorless control of induction motors. IEEE Transaction on Industrial Electronics, 55(2): 620-632. doi:10 .1109/TIE.2007.911956.

Bogiatzidis IX, Safacas AN, Mitronikas ED, and Christopoulos GA. 2012. A novel control strategy applicable for a dual AC drive with common mechanical load. IEEE Transaction on Industry Applications, 48(6): 2022-2036. doi:10.1109/TIA.2012.2226196.

Bose BK. 2001. Modern power electronics and AC drives. Prentice Hall, Upper Saddle River, NJ.

Bowes RS, Sevinc A, and Holliday D. 2004. New natural observer applied to speed-sensorless DC servo and induction motors. IEEE Transaction on Industry Applications, 51(5): 1025-1032. doi:10.1109/TIE.2004.834963.

Gunabalan R, Sanjeevikumar P, Blaabjerg F, Ojo Olorunfemi O, and Subbiah V. 2015. Analysis and implementation of parallel connected two induction motor single inverter drive by direct vector control for industrial application. IEEE Transaction on Power Electronics, 30(12): 6472-6475. doi:10 .1109/TPEL.2015.2429591.

Gunabalan R, Subbiah V, and Sanjeevikumar P. in press. Vector control of three-phase parallel connected two motor single inverter speed-sensorless drive. Turkish Journal of Electrical Engineering and Computer Science. doi:10.3906/elk-1410-48.

Guzinski J, Abu-Rub H, Diguet M, Krzeminski Z, and Lewicki A. 2010. Speed and load torque observer application in high speed train electric drive. IEEE Transaction on Industrial Electronics, 57(2): 565-574. doi:10.1109/TIE.2009.2029582.

Guzinski J, Diguet M, Krzeminski Z, Lewicki A, and Abu-Rub H. 2009. Application of speed and load torque observers in high-speed train drive for diagnostic purposes. IEEE Transaction on Industrial Electronics, 56(1): 248-256. doi:10.1109/TIE.2008.928103.

Inoue T, Azegami K, Matsuse K, Ito S, and Nakajima Y. 2011a. Characteristics of sensorless vector controlled multiple induction motor drive connected in parallel fed by a single inverter. 
In Proceedings of the IEEE International Conference on Electrical Machines and Systems, IEEE-ICEMS'11, Beijing, China, 20-23 August 2011, pp. 1-6. doi:10.1109/ICEMS.2011.6073556.

Inoue T, Azegami K, Matsuse K, Ito S, and Nakajima Y. 2011b. Dynamic performance of sensorless vector controlled multiple induction motor drive connected in parallel fed by single inverter. In Proceedings of the IEEE Industry Applications Society Annual Meeting, IEEE-IAS'11, Orlando, Florida, 9-13 October 2011, pp. 1-6. doi:10.1109/IAS.2011.6074312.

Karanayil B, Rahman MF, and Grantham C. 2007. Online stator and rotor resistance estimation scheme using artificial neural networks for vector controlled speed-sensorless induction motor drive. IEEE Transaction on Industrial Electronics, 54(1): 167-176. doi:10.1109/TIE.2006.888778.

Kawai H, Kouno Y, and Matsuse K. 2002. Characteristics of speed sensorless vector control of parallel connected dual induction motor fed by a single inverter. In Proceedings of the IEEE Power Conversion Conference, IEEE-PCC'02, Osaka, Japan, 2-5 April 2002, Vol. 2, pp. 522-527. doi:10.1109/PCC.2002.997571.

Kazuya A, Takahashi Y, Matsuse K, Ito S, and Nakajima Y. 2012. Speed characteristics of sensorless vector controlled two unbalanced induction motor drive fed by single inverter. In Proceedings of the 15th IEEE International Conference on Electrical Machines and Systems, IEEE-ICEMS'12, Sapporo, Japan, 21-24 October 2012, pp. 1-5.

Kono K, Fushimi T, and Matsuse K. 2000. Speed sensorless vector control of parallel connected induction motors. In Proceedings of the IEEE Power Electronics and Motion Control Conference, IEEE-PEMC'02, Beijing, China, 15-18 August 2000, Vol. 1, pp. 278-283. doi:10.1109/IPEMC.2000 .885414 .

Kouno Y, Kawai H, Yokomizo S, and Matsuse K. 2001. A speed sensorless vector control method of parallel connected dual induction motor fed by a single inverter. In Proceedings of the 36th IEEE Annual Meeting Conference Record of Industry Applications Conference, IEEE-IAS'01, Chicago, Illinois, 30 September 2001-4 October 2001, Vol. 2, pp. 1218-1223. doi:10.1109/ias.2001 .955652 .

Matsumoto Y, Ozaki S, and Kawamura A. 2001. A novel vector control of inverter (single) multiple induction motors drives for Shinkansen traction system. In Proceedings of the IEEE Applied Power Electronics Conference, IEEE-APEC'01, Anaheim, CA, 4-8 March 2001, pp. 608-614. doi:10.1109/ APEC.2001.911710.

Matsuse K, Kouno Y, Kawai H, and Yokomizo S. 2002. A speed-sensorless vector control method of parallel-connected dual induction motor fed by a single inverter. IEEE Transaction on Industry Applications, 38(6): 1566-1571. doi:10.1109/TIA.2002.804763.

Nishimura J, Oka K, and Matsuse K. 2007. A method of speed sensorless vector control parallelconnected dual induction motors fed by one inverter in a rotor flux feedback control. In Proceedings of the 7th IEEE International Conference Power Electronics and Drives System, IEEE-PEDS’07, Bangkok, Thailand, 27-30 November 2007, pp. 1290-1294. doi:10.1109/PEDS.2007 .4487870 .

Osawa A, Yamazaki M, and Matsuse K. 2011a. Vector control method and driving characteristics of parallel connected induction motor drives fed by a matrix converter. In Proceedings of the IEEE Industry Applications Society Annual Meeting, IEEE-IAS'11, Orlando, Florida, 9-13 October 2011, pp. 1-7. doi:10.1109/ICEMS.2011.6073557. 
Osawa A, Yamazaki M, and Matsuse K. 2011b. Vector control method of parallel connected induction motor drives fed by a matrix converter. In Proceedings of the IEEE-IAS Meeting, Orlando, Florida, 9-13 October 2011. doi:10.1109/IAS.2011.6074313.

Rashed M, Stronach F, and Vas P. 2003. A stable MRAS-based sensorless vector control induction motor drive at low speeds. In Proceedings of the IEEE International Electric Machines and Drives Conference, IEEE-IEMDC'03, Madison, Wisconsin, USA, 1-4 June 2003, Vol. 1, pp. 139-144. doi:10.1109/IEMDC.2003.1211254.

Ruxi W, Yue W, Qiang D, Yanhui H, and Zhaoan W. 2006. Study of control methodology for single inverter parallel connected dual induction motors based on the dynamic model. In Proceedings of 37th IEEE Power Electronics Specialists Conference, IEEE-PESC'06, Jeju, South Korea, 18-22 June 2006, pp. 1-7. doi:10.1109/PESC.2006.1711845.

Taniguchi M, Yoshinaga T, and Matsuse K. 2006. A speed-sensorless vector control of parallel connected multiple induction motor drives with adaptive rotor flux observers. In Proceedings of 37th IEEE Power Electronics Specialist Conference, IEEE-PESC'06, Jeju, South Korea, 18-22 June 2006, pp. 1-5. doi:10.1109/PESC.2006.1711854.

Trentin A, Zanchetta P, Gerada C, Clare J, and Wheeler PW. 2009. Optimized commissioning method for enhanced vector control of high-power induction motor drives. IEEE Transaction on Industrial Electronics, 56(5): 1708-1717. doi:10.1109/TIE.2008.2011335.

Wei S, Ruxi W, Yue W, He Y, Wang Z, and Liu J. 2006. Study of speed sensorless control methodology for single inverter parallel connected dual induction motors based on the dynamic model. In Proceedings of the 5th IEEE International Power Electronics and Motion Control Conference, IEEE-IPEMC 2006, Shanghai, China, 14-16 August 2006, Vol. 2, pp. 1-5. doi:10.1109/IPEMC.2006 .4778153 .

Wlas M, Krzeminski Z, and Toliyat HA. 2008. Neural network based parameter estimations of induction motors. IEEE Transaction Industrial Electronics, 55(4): 1783-1794. doi:10.1109/TIE.2008 .918615 .

Yamazaki M, Sakaki K, and Matsuse K. 2012. Characteristics of vector control of two induction motor drives fed by matrix converter. In Proceedings of the 15th IEEE International Conference on Electrical Machines and Systems, IEEE-ICEMS'12, Sapporo, Japan, 21-24 October 2012, pp. 1-5.

Yoshinaga T, Terunuma T, and Matsuse K. 2008. Basic characteristic of parallel connected dual induction motor drives with matrix converter. In Proceedings of the 34th Annual Conference of IEEE Industrial Electronics, IEEE-IECON'08, Orlando, Florida10-13 November 2008, pp. 584-589. doi:10.1109/IECON.2008.4758019. 